\title{
INTELLIGENT MICROENGINEERING
}

\author{
GHEORGHE, I.G. \& PAU, V.
}

Abstract: The scientific manuscript entitled Intelligent Microengineering is treating a mixture of concepts, fundaments and aplicative techniques regarding the mecathtonics field / micro-nanomecatronics, robotics / micro-nanorobotics and integronics / micro-nanointegronics, field of informational instrumentation / micronanoinstrumentation, sensors / micro-nanosensori field, transducers / micronanotransducers and actuators / micro-nanoactuators, field of micro-devices in 3D, $4 D$ and 5D for micro-nanoprocessing, inspection and integrated control and field of advanced micro-nanomanufacturing.

The main purpose of the scientific manuscript is to present the new scientific results of high-tech level in the intelligent micro-engineering, for discovering new knowledge in technical, technological and inovative domain as well as for discovering new concepts, intelligent-mechatronic / robotic and integronic systems / equipments, based on excellence research laboratories with advanced endowments in domain, for the new generations of equipments and technologies.

Key words: mecathronic; micro-nanomecathronic; robotic; micro-nanorobotic; micro-nanointegronic
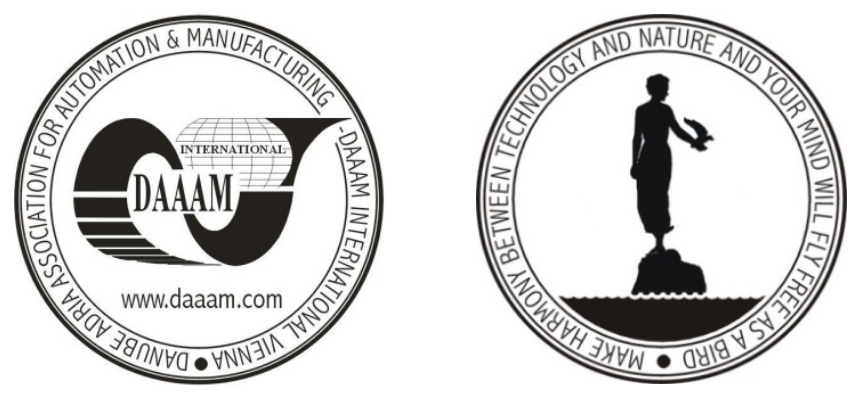

Authors' data: Univ.Prof. Dipl.-Ing. EurIng. Ph’D.Eng. Gheorghe, I. G[heorghe]*; Univ.Prof. Dipl.-Ing. Ph'D.Eng. Pau, V[alentin]**, *Politehnica University of Bucharest, Splaiul Independentei Street 313, 060042, Bucharest, Romania, ** Titu Maiorescu University 22, Dâmbovnicului Street, 4 District, 040051 Bucharest, Romania; geo@cefin.ro,v_pau@utm.ro

This Publication has to be referred as: Gheorghe, I. G[heorghe] \& Pau, V[alentin] (2009). Intelligent Microengineering, Chapter 71 in DAAAM International Scientific Book 2009, pp. 735-750, B. Katalinic (Ed.), Published by DAAAM International, ISBN 978-3-901509-69-8, ISSN 1726-9687, Vienna, Austria

DOI: $10.2507 /$ daaam.scibook.2009.71 